\title{
TRADISI MOLO SABUANG MASYARAKAT MARAFENFEN DI KABUPATEN KEPULAUAN ARU, MALUKU
}

\author{
Marius Agustinus Welliken K \\ Jurusan Manajemen Sumberdaya Perairan, Fakultas Pertanian, \\ Universitas Musamus, Merauke, Papua \\ wellikenrio@gmail.com
}

\begin{abstract}
The customary tradition of "molo sabuang" is one of the ways used by indigenous people in Aru in resolving disputes or conflicts of Ownership Rights such as land boundaries, sea boundaries and plant boundaries. The implementation of "molo sabuang" is a form of local wisdom of the community of Aru in Maluku, which serves to create a social order, and potentially has a spirit value to create peace based on local culture. "molo sabuang" tradition is one of the cultures passed down from generation to generation from ancestors to descendants in Aru Island District. "molo sabuang" is a dive without a breathing apparatus while holding on a pole that is plugged in the water. This custom can solve the domestic problems that occur in the Aru society. This custom belongs not only to the Marafenfen community but also to of all the Aru indigenous people scattered from the north to the south.
\end{abstract}

Key words: tradition of Molo Sabuang, Marafenfen communities

\section{Pendahuluan}

Manusia dalam pergaulannya tidak pernah terlepas dari tradisi dan terikat pada norma-norma yang berlaku. Norma hukum merupakan pedoman dalam kehidupan bermasyarakat untuk bertingkah laku.

Hukum adat merupakan hukum yang tidak tertulis, yang sejak dahulu kala, hidup, berkembang, dan berakar pada masyarakat adat. Walaupun hukum adat tidak tertulis namun kekuatan dari hukum adat sangat berpengaruh pada masyarakat adat dimana saksi akan diberikan kepada siapa yang melanggar hukum adat tersebut.

Menurut Ter. Haar B. BZN, hukum adat mengatur etika moral masyarakat dalam kehidupan keluarga maupun dalam kehidupan bermasyarakat yang lebih luas. Hukum adat menjadi nilai yang dapat mengatur ketertiban dan keamanan masyarakat adat.

Dalam Undang-undang nomor 17 tahun 2007 tentang rencana Pembangunan jangka panjang Nasional 2005-2007, hukum adat sebagai suatu kearifan lokal dalam pengembangan hukum nasional dihargai dan dihormati. Hal inilah yang membuktikan bahwa Pemerintah Republik
Indonesia menjamin diberlakukannya hukum adat pada setiap daerah di Indonesia, tak terkecuali di Maluku. Salah satu tradisi adat yang masih berlaku didalam kehidupan masyarakat Aru di Maluku adalah molo sabuang.

Tradisi adat molo sabuang merupakan salah satu jalan yang digunakan oleh masyarakat adat di Aru dalam menyelesaikan sengketa atau konflik "Hak Kepemilikan" misalnya batas tanah, batas laut, dan batas tanaman. Pada masyarakat adat di Aru dilakukan persidangan adat, namun apabila tidak ditemukan hasil maka salah satu jalan yang harus dilakukan oleh masyarakat adat di Aru adalah dengan dilakukannya tradisi adat molo sabuang. Adat ini dilakukan secara turun menurun dalam menyelesaikan konflk yang bersifat domistik.

Pelaksanaan molo sabuang merupakan salah satu bentuk kearifan lokal masyarakat Aru di Maluku, yang berfungsi menciptakan tatanan tantanan sosial yang humoris, dan secara potensial memiliki nilai spirit utuk menciptakan perdamaian yang berbasis budaya lokal. Pelaksanaan adat molo sabuang merupakan suatu media 
mediasi konflik yang non letigasi. Tradisi adat molo sabuang dalam menyelesaikan ketegangan sosial atau konflik sosial dalam menentukan batas tanah, air dan kepemilikan tanaman di masyarakar Aru sangatlah efektif, hal ini dikarenakan nilainilai dan aturan tersebut telah terinternalisasi dalam masyarakat dengan baik. Sehingga penghargaan dan penerimaan terhadap sebuah keputusan adat akan lebih bertahan, karena konteks sosial budaya menjadi latar keputusan dari masyarakat di Aru.

Tradisi adat Molo sabuang merupakan salah satu kebudayaan yang diwariskan secara turun temurun dari leluhur kepada anak cucu di Kabupaten Kepulauan Aru. Dalam pengertian molo sabuang adalah menyelam tanpa alat bantu pernapasan sambil memegang pada tiang yang ditancapkan didalam air. Kalau diartikan secara hurufiah, maka molo adalah "menyelam" sedangkan sabuang adalah "kayu atau jangkar yang ditancapkan didalam air".

Tradisi adat Molo sabuang akan dilakukan apabila proses penyelesain sengketa "kepemilikan" oleh pemerintah desa mengalai jalan buntuh, hal ini disebabkan adanya saling mengklaim kebenaran dari kedua pihak yang bertikai. Untuk menemukan kebenaran yang hakiki maka tida ada jalan lain selain tradisi adat molo sabuang digunakan. Pelaksanaan tradisi adat ini dapat dilakukan apabila kedua pihak menyetujuinya.

Tradisi molo sabuang dilakukan dilaut atau disungai, sesuai dengan wilayah setempat. Artinya bagi masyarakat pesisir maka akan dilakukan di laut sedangkan bagi masyarakat yang bukan pesisir maka akan dilakukan di sungai. Pelaksanaan tradisi adat molo sabuang akan menunjukkan kebenaran dengan sangat cepat, dimana yang bukan pemilik akan dengan cepat keluar dari dalam air dengan waktu yang singkat. Hal ini bukan disebabkan karena sang pemilik sudah terbiasa dalam menyelam melainkan karena doa adat yang telah di naikan kepada Jurjiduai Darapopopane (Tuhan Sang Pencipta) dan Jomjagasira Datuktantana (Leluhur).

Gambaran diatas merupakan bentuk kepercayaan masyarakat Aru yang masih dipertahankan hingga saat ini. Mereka sangat percaya dan nyakiin apabila doa adat yang dinaikan kepada Jurjiduai Darapopopane (Tuhan Sang Pencipta) dan Jomjagasira Datuktantana (Leluhur) akan terjawab segera dalam tradisi adat molo sabuang.

Realitas sosial masyarakat adat di Kabupaten kepulauan Aru, yang menaru kepercayaannya terhadap Jurjiduai Darapopopane (Tuhan Sang Pencipta) dan Jomjagasira Datuktantana (Leluhur) dalam mencari kebenaran membuat tradisi adat molo sabuang tetap hadir hingga saat ini.

\subsection{Pelaksanaan Tradisi Adat "molo sabuang”}

\subsubsection{Gambaran umum dari Kabupaten Kepulauan Aru.}

Desa Marafenfen terletak dibagian selatan Kabupaten Kepulauan Aru, kabupaten ini masih terhitung sangat muda. Berdasarkan UU No 40 Tahun 2003 tentang pemekaran beberapa kabupaten diMaluku, salah satunya adalah Kabupaten Kepulauan Aru yang wilayah admistrasinya berasal dari kabupaten Maluku Tengah. Secara umum Kabupaten Kepulauan Aru memiliki topografi yang datar dan pesisir panatai yang berawarawa.

\subsubsection{Realitas Masyarakat Marafenfen}

Marafefen terletak dibagian selatan Kabupaten Kepulauan Aru, untuk menempuh desa ini 10-12 jam dari pusat kabupaten (kota Dobo) dengan menggunakan transportasi laut. Aru selatan terbagi dalam dua kecematan yaitu kecematan Aru Selatan Timur terdiri dari 20 desa, dan kecematan Aru selatan 11 desa, dimana desa Marafenfen berada. Desa Marafefen berada pada hulu sungai 
yang berjarak $15 \mathrm{~km}$ dari pantai serwatu. Sejarah singkat terbentuknya desa marafenfen berawal dari bergabungnya dua marga yaitu Gaelagoy dan Bothmir maka terbentuknya desa Marafenfen yang awalnya bernama mala-mala (redy/kayu tajam). Istilah Marafenfen (sungai seberang) sehingga muncullah nama Marafenfen dan digubakan menjadi Marafenfen sampai sekarang.

\subsubsection{Sistem Pemerintahan Adat Desa Marafenfen}

Struktur masyarakat dimaluku secara umum memiliki dua bentuk yaitu kelompok yang terbentuk berdasarkan garis keturunan (geneologis) dan kelompok yang terbentuk berdasarkan wilayah tempat tinggal (teritorial). Susunan masyarakat mulai dari keluarga sebagai unit terkecil.

\section{a. Matarumah}

Kesatuan kelompok geneologis yang besar sesudah keluarga adalah matarumah, rumatau, atau lumatu. Sebutan untuk kata "ruma" ini berbeda tempat sesuai dengan dialek setempat. Menurut dialek masyarakat Saparua disebut Lumal, dialek Nusalaut disebut Rumal, dialek Haruku disebut ruma, dialek Hila dan Asilulu luma (Efendi, 1987).

Secara harifiah, "ruma" berarti Rumah dan "tau" berarti "isi", maka rumatau berarti rumah yang didiami bersama-sama oleh orang-orang yang seketurunan dan keanggotaannya tersusun menurut garis bapak. Dari matarumahmatarumah inilah berkembang susunan masyarakat.

\section{b. Soa/Marga}

Di Maluku Soa adalah suatu persekutuan teritorial geneologis. Soa merupakan suatu wilayah menjadi bagian dari suatu pertunas atau negeri. Dibawah soa ini bernaung beberapa rumatau. Didalam kenyataannya rumatau-rumatau dalam soa tersebut tidak seketurunan. Mereka ada yang berasal dari keturungan yang berbedah-bedah yang secara kebetulan mencapai wilayah yang sama.
Dalam hal ini yang lebih menonjol untuk mereka bergabung adalah unsur teritorial dan unsur geneologis (Efendi, 1987: 129). c. Negri

Istilah negeri sebetulnya bukan berasal dari bahasa asli masyarakat Maluku, besar kemungkinan berasal dari bahasa melayu. Suatu negeri adalah persekutuan teritorial yang terdiri atas beberapa soa yang pada umumnya berjumlah paleng sedikit tiga kelompok soa.

\subsubsection{Diskripsi Tradisi Adat "Molo Sabuang"}

Harus diakui bahwa kehadiran masyarakat adat telah ada sejak dahulu adalah bukti bahawa masyarakat adat tumbuh dan berkembang tanpa adanya sistem politik yang idielisme. Masyarakat marafenfen merupakan masyarakat adat yang masih mempercayai leluluhur mereka dengan sangat kental. Menurut Cooley, (1961) Penggunaan bahasa tanah (pribumi), dalam setiap upacara adat bukan saja bukti keabsahan, tapi lebih jauh lagi bahwa penggunaan bahasa tanah secara langsung memberikan kepercayaan kepada leluhur. Sehingga kepercayaan kepada arwah leluhur mereka wujudkan dalam setiap kehidupan. Pengakuan terhadap masyarakat adat pada hakekatnya merupakan pengakuan dan penghargaan terhadap nilai-nilai kultur masyarakat. Atas dasar itulah maka nilai-nilai kultur masyarakat dipahami, dan dikembangkan sehingga dianggap sebagai sumber-sumber yang harus dipelajari, dipelihara dan dilanjutkan sehingga dapat dimanfaatkan.

\subsection{Arti, Alasan dan Tujuan Molo Sabuang.}

Kata molo sabuang adalah menyelam tanpa alat bantu pernapasan sambil memegang pada tiang yang ditancapkan didalam air. Kalau diartikan secara hurufiah, maka molo adalah "menyelam" sedangkan sabuang adalah "kayu atau jangkar yang ditancapkan didalam air". Sikap bertahan didalam air bukan karna 
mahir dalam menyelam melainkan yang membuat seseorang tidak dapat bertahan didalam air karena berar-benar itu bukan miliknya. Maka tujuan dari tradisi adat molo sabuang adalah mencari kebenaran yang hakiki.

Menurut hasil wawancara Umar Djabumona dalam Sipahelut (2012), Tradisi adat molo sabuang merupakan warisan budaya bagi masyarakat Aru. Tradisi adat ini kenal oleh setiap anak cucu masyarakat Aru. Tardisi adat ini diwariskan dengan tujuan mendapatkan kebenaran yang hakiki. Apabila ada sengketa atau konflik batas-batas petuanan yang dibawah dan diselesaikan secara kekelurgaan di depan pemerintah desa dan tidak mencapai keputusan siapa pemiliki yang sebenarnya, maka jalan satu-satunya adalah dengan dilakukannya tradisi adat molo sabuang.

Lebih jauh Umar dalam Sipahelut (2012), mengatakan bahwa tradisi adat ini sangat beresiko, dapat membawa kematian bagi pihak yang tidak ingin mengakui kekelahannya. Dalam melakukan tradisi adat ini diperlukan beberapa tahap yang harus dilakukan oleh pemangku adat kepada pihak-pihak yang bersengketa.

Menurut hasil wawancara Karl dalam Sipahelut (2012), bahwa praktek dalam tradisi adat Molo Sabuang sama halnya dalam mencari kotak hitam pada pesawat, dimana pada saat kotak hitam dibuka maka kebenaran dari jatuhnya pesawat dapat diketahui. Dan itulah salah satu cara untuk mengetahui penyebab jatuhnya pesawat. Karena itu adat molo sabuang tidak selamanya digunakan, namun penggunaan adat ini karena adanya desakan dari setiap kubu yang bersengketa atau bertikai dan tidak ada jalan lain lagi maka tradisi adat molo sabuang merupakan penyelesaian yang terakhir.

\subsection{Mekanisme Praktek Tradisi Adat "Molo Sabuang"}

Praktik Tradisi adat molo sabuang merupakan salah atu kearifian lokal yang memiliki nilai-nilai hukum dan spirit dalam menciptakan perdamaian. Untuk menyelesaikan persoalan-persoalan dalam masyarakat maka Badan Saniri Rajapatih yang beranggotakan Raja/kepala Desa, kepala Soa, Kepala Kewang, dan Marinyo serta badan saniri lengakap sangat berperan penting dalam hal ini.

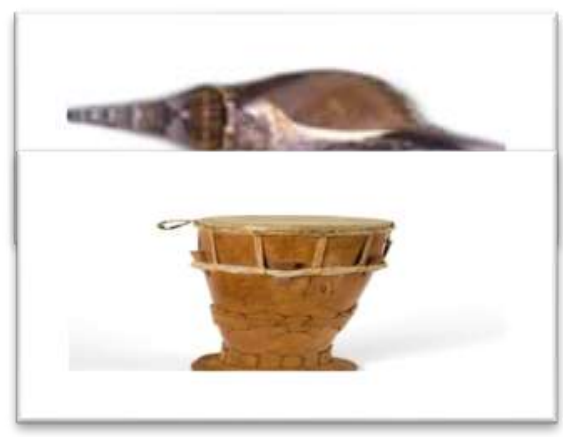

Gambar 1 Tahuri/ kulia bia dan Tifa (sumber: Dinas Parawisata dan kebudayaan kabupaten kepulauan Aru, 2010

Untuk tahap tradisi adat molo sabuang diperlukan beberapa tahap:

\section{Tahap Awal}

Adanya persoalan hak kepemilikan atas sebuah bendah (tanah, hasil hutan atau kepemilikan lainnya) antar individu maka dilaporakan kepada badan saniri rajapatih (badan eksikutif) untuk diselesaikan secara kekeluargaan. Meskipun dalam proses kekeluargaan peneyelesaian tidak didapat karena adanya kebenaran berganda maka tradisi molo sabuang diambil oleh masingmasing yang bertikai dalam hal saling menantang untuk mencari kebenaran. Namun tradisi adat ini dilakukan secara kekeluargaan dengan kesepakatan dari kedua pihak yang bertikai. Maka Badan Saniri Rajapatih mengundang raja Saniri Lengkap untuk melakukan penyelesaian. Peretemuan antara ketiga pihak dilakukan dengan tujuan meneyelesaikan persoalan tanpa keluar dari rasa kekeluargaan yang dimiliki. Pertemuan akan mengahsilkan waktu dan tempat dimana akan dilakukan tardisi adat tersebut.

Menurut Bapak Yacobias dalam Sipahelut (2012), persyaratan untuk 
melakukan tradisi adat ini haruslah lakilaki dewasa. Interval waktu yang ditentukan untuk berlangsungnya molo sabuang adalah 3-6 hari terhitung dari hasil pertemuan terakir dari tiga arah. Hasil dari pertemuan dimaksud maka Raja/Kepala Desa mempersilakan Maweng atau pendeta untuk doa adat dengan maksud untuk memohon restu dari Jurjiduai Darapopopane (Tuhan Sang Pencipta) dan Jomjagasira Datuktantana (Leluhur) sehingga tidak ada kecurangan. Selesai pertemuan dari tiga arah maka semua pihak yang bertikai diperbolehkan pulang kerumah masing-masing dan dilarang keluar desa hingga masalah ini terselesaikan dengan baik.

\section{Proses Adat Molo Sabuang}

Tempat pelaksanaan adat molo sabuang adalah sungai atau laut yang esuai dengan desa setempat. Ukuran air harus setinggi dada orang dewasa atau sekitar $60-100 \mathrm{~cm}$. Selain tempat benda-benda yang harus disiapkan adalah kayu (sabuang), gong, kerang (kulit bia/tahuri) atau tifa yang akan digunakan sebagai tanda bahwa akan di mulai menyelam (molo). Dalam Sipahelut 2012, dijelaskan sebelum diadakannya adat molo sabuang kepala desa telah memberikan marinyo atau pengumuman kepada seluruh masyarakat bahwa akan diadakan adat molo sabuang terhadap kedua pihak yang bertikai. Sehingga masyarakat akan berkumpul di tempat pelaksanaan molo sabuang. Tiba saat untuk melakukan tradisi adat molo sabuang dimana semua pihak yang terlibat kan berkumpul didalam rumah kepala desa setelah itu melakukan perjalanan menuju lokasi yang akan diadakan adat molo sabuang. Sambil berjalan pihak yang bertikai akang memikul kayu (sabuang) mereka masing-masing dan dibawah ketempat yang akan diadakan molo sabuang dengan disaksikan oleh masyarakat. Sesampainya dilokasi tempat pelaksanan kepala adat atau tuan tanah akan menancampakan sabuang dari masing-masing yang bersengketa sebelum dibacakan doa dari Mauweng. Selesai menancapkan sabuang maka Raja akan mempersilakan penyelam untuk turun kedalam air dan memegang masing-masing tiang kayu sabuang yang sudah ditancapkan.

Penyelam dalam kondisi siaga didalam air, setelah mendengar tiupan kuli bia sebagai aba-aba oleh Marinyo, maka penyelam segera masuk kedalam air (molo) sambil memegang tiang kayu sabuang. Bagi siapa yang terlebih dahulu mengeluarkan kepala maka dia bukan pemiliknya dan sebaliknya, seperti terlihat pada gambar 2 .

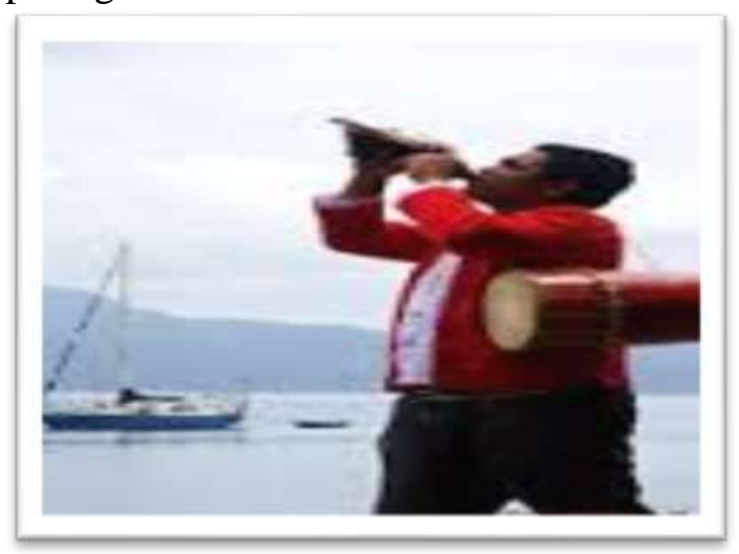

Gambar 2. Proses Peniupan Tahuri/ kulia Bia sebagai tanda tradisi adat molo sabuang dimulai

\section{Penyerahaan Kepemilikan}

Sebelum melakukan peneyerahan kepemilikan, Raja dan Kepala Soa memberikan arahan kepada masing-masing keluarga yang bertikai bahwa segala sesuatu yang dilakukan dan diminta dalan doa adat akan menunnjukan kebenarannya. Selesai arahan dilakukan maka dilanjukan dengan proses penyerahan kepemilikan yang akan dilakukan oeh Kepala adat/ Tuan tanah.

\subsection{Ketaatan masyarakat Maafenfen Terhadap Tradisi Adat Molo Sabuang.}

Secara umum penyelesaian sengketa dalam masyarakat marafenfen masih berpusat pada kepala desa. Bagi mereka kepala desa merupakan penjelmaan dari 
para leluhur sehingga keputusannya sangat dipatuhi oleh masyarakat. Selain kepala desa terdapat juga kepala soa, pendeta tokoh adat yang turut membantu dalam menyelesaikan persoalan yang dihadapi. Namun bila persoalan tidak dapat di selesaikan maka tradisi adat molo sabuang akan dilakukan dengan persetujuan yang bertikai.

Proses penyelesain dengan Tradisi adat molo sabuang membuat masyarakat sangat takut untuk melanggar keputusan dari adat ini karena, sangsi yang akn didapat apabila melnggara adat ini adalah kematian sesuai dengan isi doa adat yang telah diucapkan. Hukuman atau sangsi ini berasal dari Jurjiduai Darapopopane (Tuhan Sang Pencipta) dan Jomjagasira Datuktantana (Leluhur). Inilah sikap masyarakat marafefen terhadap ketaan mereka pada adat yang mereka percayai.

\section{Simpulan}

Berdasarkan uraian diatas, diatas maka dapat disimpulakan bahwa : praktek tradisi adat molo labuang merupakan kearifan lokal yang diwariskan oleh leluhur kepada masyarakat kepulauan Aru yang harus dipertahan dan dilestarikan. Dengan adanya tradisi adat ini bisa menyelesaikan persoalan domestik yang terjadi dalam masyarakat Aru. Adat ini bukan hanya milik masyarakat Marafenfen melainkan milim semua masyarakat adat Aru yang tersebar dari dari wilayah utara sampai selatan. Adat ini dipahami sebagai nilai untuk mencapai kebenaran yang hakiki.

Proses penyelesain dengan Tradisi adat molo sabuang membuat masyarakat sangat takut untuk melanggar keputusan dari adat ini karena, sangsi yang akan didapat apabila mealnggar adat ini adalah kematian sesuai dengan isi doa adat yang telah diucapkan. Hukuman atau sangsi ini berasal dari Jurjiduai Darapopopane (Tuhan Sang Pencipta) dan Jomjagasira Datuktantana (Leluhur) hal inlah yang membuat masyarak Aru taat kepada adat. Bagi masyarakat Aru adat ini dapat meneylesaikan maslah tanpa menimbulkan dendam antara satu dengan yang lain.

Karena itu molo sabuang sebagai budaya dari kepulauan Aru yang seumpama rambu lalulintas yang memberikan makna kepatuhan bagi masyrakat kepulauan Aru tanpa terkecuali. Dengan demikan makna molo sabuang dapat diformulasikan sebagai norma yang mendorong sekaligus membenahi sebuah hubungan yang retak karena perbedaan presepsi terhadap suatu persoalan.

\section{Daftar Pustaka}

Cooley, Frank. 1961. Mimbar dan Tahta Hubungan Lembaga-Lembaga Keragaman dan Pemerintahan di Maluku Tengah. Jakarta. Disertasi.

Efendi, Ziwar. 1987. Hukum Adat Ambon Lease. PT Pradmy Paramita: Jakarta

Sipahelut, J. A.2012. "Media Resolusi Konflik Berbasis adat molo sabuang pada masyarakat desa Marafenfen di Kabupaten Aru".UKSW. Tesis.

Ter, Haar B. BZN, DLL. 1973. Hukum Adat Polemik Ilmiah. Jakarta. 